\title{
Cardiovascular drugs and COVID-19 clinical outcomes: a systematic review and meta-analysis of randomized controlled trials
}

\author{
Innocent Asiimwe ${ }^{1}$, Sudeep Pushpakom², Richard Turner ${ }^{1}$, Ruwanthi Kolamunnage-Dona ${ }^{1}$, \\ Andrea L. Jorgensen ${ }^{2}$, and Munir Pirmohamed ${ }^{3}$ \\ ${ }^{1}$ University of Liverpool \\ ${ }^{2}$ University of Liverpool Faculty of Health and Life Sciences \\ ${ }^{3}$ University of Liverpool Institute of Translational Medicine
}

February 8, 2022

\begin{abstract}
Aims: To update our previously reported systematic review and meta-analysis of observational studies on cardiovascular drug exposure and COVID-19 clinical outcomes by focusing on newly published randomized controlled trials (RCTs). Methods: More than 500 databases were searched between 1-Nov-2020 and 2-Oct-2021 to identify RCTs that were published after our baseline review. One reviewer extracted data with other reviewers verifying the extracted data for accuracy and completeness. Results: After screening 22,414 records, we included 24 and 21 RCTs in the qualitative and quantitative syntheses, respectively. The most investigated drug classes were angiotensin-converting enzyme inhibitors (ACEIs)/angiotensin receptor blocker (ARBs) and anticoagulants, investigated by 10 and 11 studies respectively. In meta-analyses, ACEI/ARBs did not affect hospitalization length (mean difference/MD -0.42, 95\% CI -1.83; 0.98 days, $\mathrm{n}=1183$ ), COVID-19 severity (risk ratio/RR 0.90, 95\% CI 0.71; 1.15, $\mathrm{n}=1661$ ) and mortality (RR $0.92,95 \%$ CI $0.58 ; 1.47, \mathrm{n}=1646)$. Therapeutic anticoagulation also had no effect (hospitalization length MD -0.29, 95\% CI -1.13 to 0.56 days, $\mathrm{n}=1449$; severity RR $0.86,95 \%$ CI $0.70 ; 1.04, \mathrm{n}=2696$; and, mortality RR 0.93 , 95\% CI 0.77;1.13, n=5689). Other investigated drug classes were antiplatelets (aspirin, 2 trials), antithrombotics (sulodexide, 1 trial), calcium channel blockers (amlodipine, 1 trial) and lipid modifying drugs (atorvastatin, 1 trial). Conclusion: Moderate- to high-certainty RCT evidence suggests that cardiovascular drugs such as ACEIs/ARBs are not associated with poor COVID-19 outcomes, and should therefore not be discontinued. These cardiovascular drugs should also not be initiated to treat or prevent COVID-19 unless they are needed for an underlying currently approved therapeutic indication.
\end{abstract}

\section{Hosted file}

COVID_manuscript_210122.docx available at https://authorea.com/users/398687/articles/555741cardiovascular-drugs-and-covid-19-clinical-outcomes-a-systematic-review-and-metaanalysis-of-randomized-controlled-trials

\section{Hosted file}

Figure 1.docx available at https://authorea.com/users/398687/articles/555741-cardiovasculardrugs-and-covid-19-clinical-outcomes-a-systematic-review-and-meta-analysis-ofrandomized-controlled-trials

\section{Hosted file}

Figure 2.pdf available at https://authorea.com/users/398687/articles/555741-cardiovasculardrugs-and-covid-19-clinical-outcomes-a-systematic-review-and-meta-analysis-ofrandomized-controlled-trials 


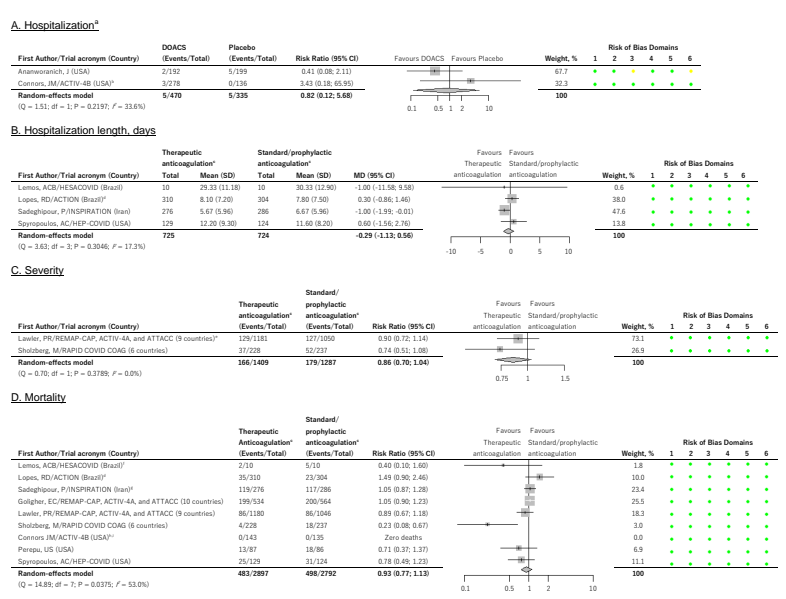

Figure 3. 